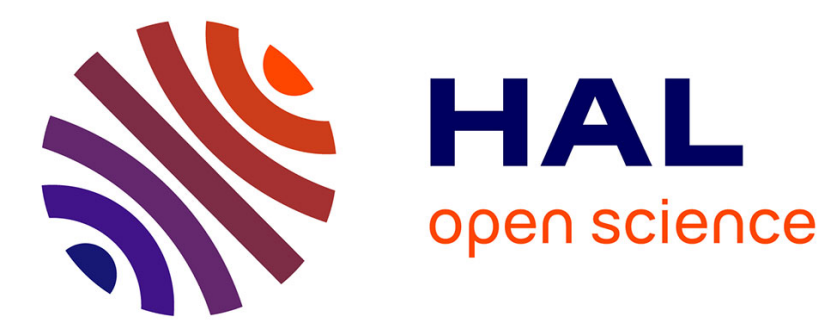

\title{
Experimental study of pulsed microwave discharges at pressures ranging over five orders of magnitude
}

S.A. Shcherbanev, Mhedine Ali Cherif, Svetlana Starikovskaia, Yuji Ikeda

\section{To cite this version:}

S.A. Shcherbanev, Mhedine Ali Cherif, Svetlana Starikovskaia, Yuji Ikeda. Experimental study of pulsed microwave discharges at pressures ranging over five orders of magnitude. Plasma Sources Science and Technology, 2019, 28, 045009 (10pp). 10.1088/1361-6595/aae765 . hal-02406808

\section{HAL Id: hal-02406808 \\ https://hal.science/hal-02406808}

Submitted on 23 Nov 2020

HAL is a multi-disciplinary open access archive for the deposit and dissemination of scientific research documents, whether they are published or not. The documents may come from teaching and research institutions in France or abroad, or from public or private research centers.
L'archive ouverte pluridisciplinaire HAL, est destinée au dépôt et à la diffusion de documents scientifiques de niveau recherche, publiés ou non, émanant des établissements d'enseignement et de recherche français ou étrangers, des laboratoires publics ou privés. 


\title{
Experimental study of pulsed microwave discharge between 0.2 mbar and 8 bar.
}

\author{
S. A. Shcherbanev ${ }^{1}$, M. Alicherif ${ }^{1}$, S. M. Starikovskaia ${ }^{1}$, \\ Yu. Ikeda ${ }^{2}$ \\ ${ }^{1}$ Laboratory of Plasma Physics (CNRS, Ecole Polytechnique, UPMC, Univ. \\ Paris-Sud, Observatoire de Paris, Paris-Saclay University, Sorbonne Universities), \\ Ecole Polytechnique, route de Saclay, 91128 Palaiseau, France \\ ${ }^{2}$ Imagineering Inc., 7-4-4 Minatojima-Minami, Chuo, Kobe 650-0047 JAPAN \\ E-mail: svetlana.starikovskaia@lpp.polytechnique.fr
}

\begin{abstract}
.
Microwave discharge igniter (MDI) is a discharge system developed to initiate combustion at the conditions of automotive engines. The MDI uses a sequence of $N=700$ microwave $(2.45 \mathrm{GHz})$ pulses $100 \mathrm{~ns}$ in duration separated by $1 \mu \mathrm{s}$. The initial breakdown is provided by the first microwave pulse, $5 \mu \mathrm{s}$ in duration. The aim of pulsing the microwave signal is to keep an optimal combination of parameters when, even at elevated pressures, (i) the discharge is spread over a maximum possible volume; (ii) the plasma in non-equilibrium. Properties of plasma produced by MDI igniter in non combustible gas mixtures at ambient gas temperature and gas pressure between 0.2 mbar and 8 bar were studied experimentally. Discharge spatial structure was analyzed with the help of time-resolved ICCD imaging. Optical emission spectra in near UV taken in different pulses provided the information about rotational and vibrational temperatures. The electric field was estimated on the basis of ratio of emission of the second positive and the first negative systems of molecular nitrogen.
\end{abstract}

Keywords: pulsed microwave discharge, non-equilibrium plasma, initiation of combustion 


\section{Introduction}

In the last few decades, the need for a sustainable combustion led to numerous experimental and kinetic modeling studies. The concept of plasma-assisted combustion (PAC) has been suggested and developed [1-8]. The use of different type of discharges was investigated including nanosecond pulsed discharges, gliding arcs, microwave, corona, DBDs and plasma torches [8]. This interest is stimulated by a wide range of potential applications: ignition of fuel-air mixtures at moderate gas densities and high velocity gas flows, including ignition in supersonic flows, combustion sustaining or enhancement by plasma at atmospheric pressure, stimulation of combustion of lean mixtures (mixtures where the fuel-to-oxidizer ratio is less than unity). The possibility to control plasma parameters, in particular the mean electron energy, provides the opportunity to change the energy branching in the plasma from mainly excitation of low-energetic vibrational degrees to excitation of high-energetic electronic states, dissociation and ionization. Combination of efficient excitation with a fast energy relaxation from electronically excited atoms and molecules (so-called "fast gas heating" [9]) leads to (i) dissociation of oxygen and fuel molecules; (ii) increase of temperature providing development of a chain reaction of combustion. Increase of interest of industrial partners to the PAI/PAC can be proved by the fact that ignition by nonequilibrium plasmas is widely discussed in the engineering community [10].

One of the discharges recently used for plasma-assisted ignition is a pulsed microwave discharge: a device called Microwave Discharge Igniter (MDI) [11, 12] has been developed and successfully tested. The MDI power supply provides $2.45 \mathrm{GHz}$ bursts with a given duty cycle ratio. It was shown [13] that the MDI fits to the standard geometry of a spark ignition engine and provides an efficient ignition of lean combustible mixtures at pressures up to 10 bars. To optimize the plasma action from the microwave pulsed discharge on a gas mixture, a parametric study of plasma parameters is needed.

The analysis of the literature shows that the microwave discharge has been widely investigated during the last thirty years regarding to plasma chemistry applications. At low and moderate pressures, the microwave plasma was studied for chemical vapor deposition (CVD) [14,15], removal of volatile air pollutants [16], ignition of supersonic flows and so on. The effect of frequency and duty cycle of a pulsed microwave $2.45 \mathrm{GHz}$ plasma on the chemical vapor deposition of diamond has been studied at $P=40$ Torr [15] using a gas mixture of $0.6 \% \mathrm{CH}_{4}$ by volume in $\mathrm{H}_{2}$. Hydrogen temperature, by Doppler broadening of Balmer lines and by the rotational temperature of $\mathrm{d}^{3} \Pi_{u}$ state of $\mathrm{H}_{2}$ was measured in the microwave discharge in hydrogen at $P=133 \mathrm{~Pa}$ [17]. Dynamics of temperature increase in pulsed microwave discharge in nitrogen, $P=1-100 \mathrm{mbar}$ was studied in [18]; $500 \mu$ s pulses with a repetition rate $75 \mathrm{~Hz}$ were used. At the power $1.3 \mathrm{~kW}$, a fast $\left((5-10) \cdot 10^{6} \mathrm{~K} / \mathrm{s}\right)$ gas heating was observed during the beginning of the pulse with a subsequent saturation of the temperature. Actinometry technique based

on monitoring the $\operatorname{Ar}\left({ }^{2} P_{9}, 8115 \AA, 13.08 \mathrm{eV}\right)$ line and the $\mathrm{Hg}(\mathrm{n}=5,4340 \AA, 13.06 \mathrm{eV})$ line was used in [18] to compare the atomic hydrogen density in continuous and pulsed 
MW discharges in the CVD reactor under conditions of a continuous discharge and a repetitive pulsed discharge in hydrogen-methane mixtures at pressures of $10-150$ Torr. The methane concentration was varied from 0.1 to $10 \%$, the microwave $(2.45 \mathrm{GHz})$ pulse duration was $5 \mathrm{~ms}$, and the repetition rate was equal to $100 \mathrm{~Hz}$. It was shown that use of the pulsed discharge provides higher stationary densities of atomic hydrogen. Finally, the microwave discharge in propane-air mixture at static air pressure from 10 to 100 Torr was used to trigger combustion in a supersonic flow, $M=2$ [19].

As the discharge is spatially homogeneous and occupies a big volume at low gas density, the moderate pressures, $P<100$ Torr, is the most studied domain from the point of view of kinetics and plasma properties. At atmospheric pressure, the microwave induced plasmas (MIPs) were developed as compact sources of three possible types: resonant cavity plasmas; free expanding torches and microplasmas. The detailed description of the microwave plasmas operation and diagnostics at atmospheric pressure can be found in the review [20]. The resonant cavity microwave sources are the sources generating a standing wave and so minimizing the losses; the torches and the microplasmas are less geometry-depended; although their efficiency is lower, the electrode system can be adapted for a particular application.

Plasma produced by microwave discharge at atmospheric pressure can be different depending upon the parameters of the experiment; electron density, $n_{e}$, and electron temperature, $T_{e}$ can be between the parameters of a DC glow and arc discharge. High pressure and high power microwave discharges were studied mainly for laser applications: for example, VUV emission of Xe and Kr has been measured in the high power $\left(10^{7} \mathrm{~W} / \mathrm{cm}^{3}\right)$ high-pressure $(10 \mathrm{~atm})$ pulsed microwave discharge [21].

Pulsed microwave discharge studied in the present paper develops at $P \geq 1 \mathrm{~atm}$. The aim of the paper was to study the nonequilibrium character of the discharge depending upon gas pressure.

\section{Experimental setup}

A general scheme of the experimental setup is shown in figure 1. The discharge was initiated in the microwave discharge igniter (MDI) mounted in the high pressure (HP) chamber. The chamber is made of stainless steel and equipped with three optical quartz windows of $15 \mathrm{~mm}$ in thickness and of $50 \mathrm{~mm}$. The chamber was pumped down to 0.1 mbar by a rotary pump (Edwards Xds 10) before each experiment and filled with the gas mixture under study.

The parameters of the pulse burst and the sequences of the pulses were controlled by the external controller connecting the power supply and the amplifier. High voltage pulses passed through the microwave circulator and the signals reflected from the microwave discharge igniter were dumped in the dummy load. To adjust the power of the incident high voltage pulses, the signal from the MW circulator was applied to LeCroy WaveRunner $600 \mathrm{MHz}$ oscilloscope through $60 \mathrm{~dB}$ attenuator. To synchronize the optical spectroscopy measurements with the discharge, a custom made current probe 
was used.

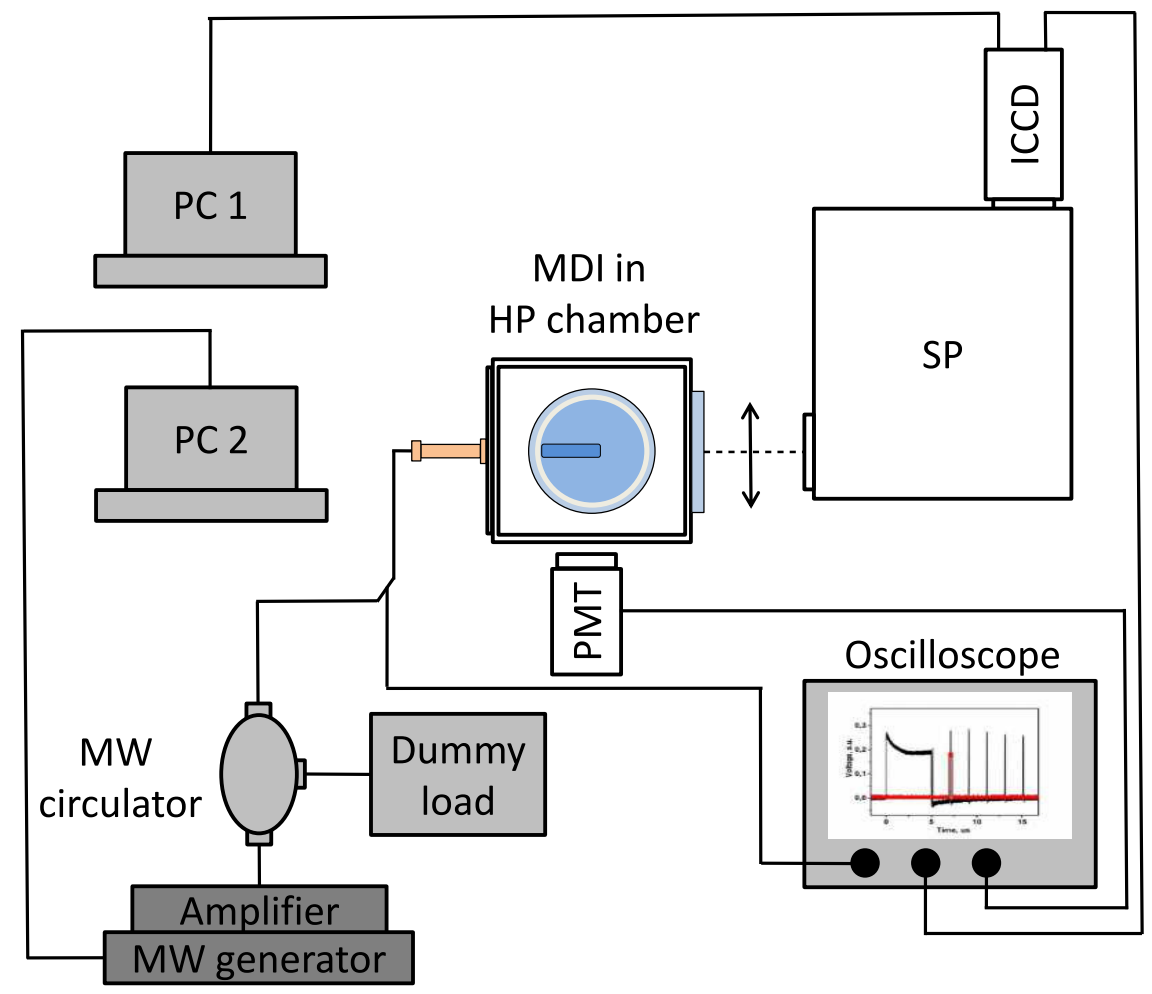

Figure 1. General scheme of the experimental setup. MDI, microwave discharge igniter; HP, high pressure; PC, personal computer; SP, spectrometer

To study the spatial structure and the development of the discharge, the images of the discharge were obtained with $\mathrm{Pi}-\mathrm{Max} 4$ Princeton Instruments ICCD camera equipped by Edmund Optics $50 \mathrm{~mm}$ FL high resolution lens. The camera was synchronized with the discharge by a triggering TGP 110 generator producing the TTL pulse. The spectra of the discharge were taken in the wavelength range $300-800 \mathrm{~nm}$. To collect the radiation in the considered wavelength, the ACTON SP-2500i (Princeton Instruments) spectrometer was used. The spectrometer was equipped with three diffraction gratings 600 (blaze on $300 \mathrm{~nm}$ ), 1200 (blaze on $500 \mathrm{~nm}$ ) and 2400 (blaze on $240 \mathrm{~nm}$ ) lines per $\mathrm{mm}$. The slit function of the spectrometer was measured experimentally using Ar:Hg lamp.

To select the number of the pulse for the following study, the time-resolved optical emission was examined. The emission was selected by a narrow band $(\lambda=340 \pm 5 \mathrm{~nm})$ Thorlabs filter and detected by Hamamatsu H6610 photomultiplier connected to LeCroy WaveRunner oscilloscope. For the selected pulse, the spectra of a few molecular bands were measured as a function of initial gas pressure and of the gas mixture composition. Reduced electric field, rotational and vibrational temperatures were analyzed. 


\begin{tabular}{|l|l|l|}
\hline & Burst 1 & Burst 2 \\
\hline f, GHz & \multicolumn{2}{|c|}{2.45} \\
\hline $\mathrm{P}, \mathrm{kW}$ & \multicolumn{2}{|c|}{1.6} \\
\hline$t_{p}, \mathrm{us}$ & 5.1 & 1 \\
\hline$t_{w}, \mathrm{us}$ & 5 & 0.1 \\
\hline$N_{p}$ & 1 & 700 \\
\hline
\end{tabular}

Table 1. parameters of the pulses used in the present work

The spectra of selected molecular bands were analyzed as a function of the pulse number and as a function of initial gas pressure. They were different bands of the second positive system of molecular nitrogen $\left(\mathrm{N}_{2}\left(\mathrm{C}^{3} \Pi_{u}\right)-\mathrm{N}_{2}\left(\mathrm{~B}^{3} \Pi_{g}\right)\right.$ transition); the first negative system $\mathrm{N}_{2}^{+}\left(\mathrm{B}^{2} \sum_{u}^{+}-\mathrm{X}^{2} \sum_{g}^{+}\right)$, atomic hydrogen (Balmer series) and atomic lines of electrode material. The slit function of the system was measured experimentally using Ar:Hg lamp. The rotational and vibrational temperatures were calculated by fitting the experimental spectra with the help of SPECAIR [22] software.

The parameters of the microwave pulses used in the present work and a scheme illustrating the sequence of the pulses are presented in Table 1 and in figure 2 respectively. The first burst (burst 1) was used to initiate the breakdown of the discharge gap. The burst contained the only MW $(f=2.54 \mathrm{GHz})$ pulse of the width $t_{W}=5 \mu \mathrm{s}$. The total duration of the pulse and of the pause after the pulse was equal to $t_{p}=5.1 \mu \mathrm{s}$. The second burst was burst sustaining plasma in the gap. It contained $N=700$ pulses $(f=2.54 \mathrm{GHz})$ each $t_{W}=100 \mathrm{~ns}$ in width, with a distance between the pulses of $t_{p}=5 \mu \mathrm{s}$. The power of the MW radiation was equal to $1.6 \mathrm{~kW}$.

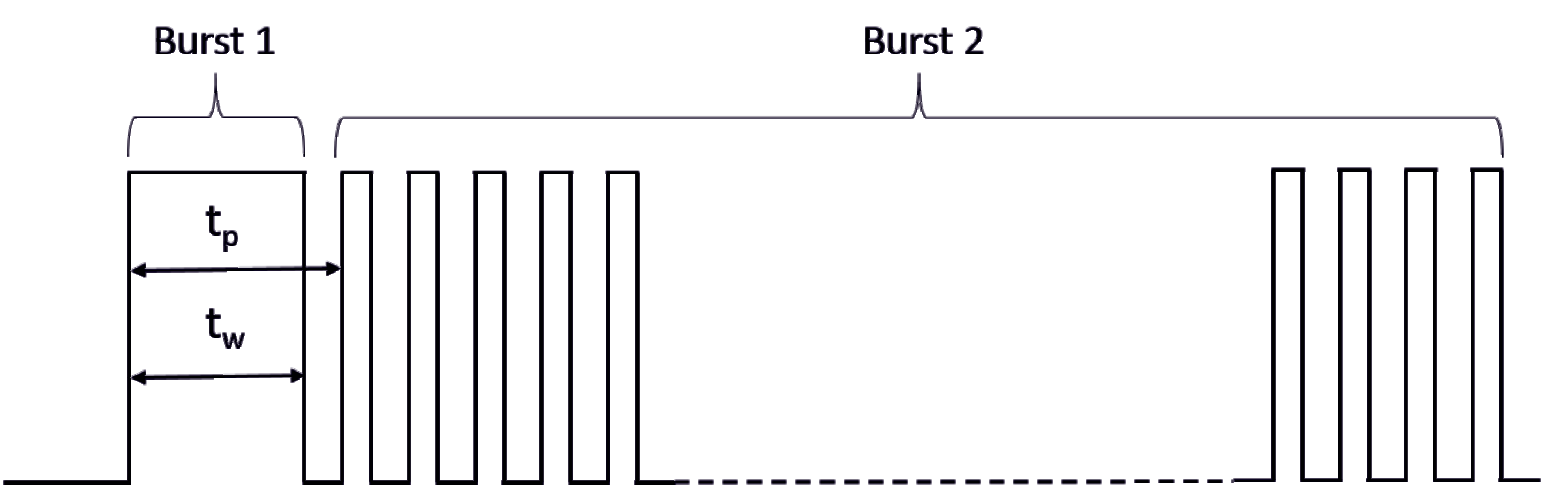

Figure 2. Sequence of the high voltage microwave pulses

The MDI igniter is presented schematically in figure $3 \mathrm{a}$. The microwave radiation is delivered from the MW connection point $C 1$ via the resonating cavity $C 2$ to the central electrode $L$. The high-voltage electrode (the igniter tip) $C 3$ is a metal cylinder in the center of igniter; the discharge gap is formed by four metal electrodes surrounding the $C 3$ electrode. The interelectrode gap is equal to $0.8 \mathrm{~mm}$, and the external diameter of the electrode system is equal to $4.5 \mathrm{~mm}$ (see the photo in figure $3 \mathrm{~b}$ ). 


\section{C1: MW connection point C2: Resonating cavity (dielectric ceramic materials) $L:$ Central electrode C3: Igniter tip}

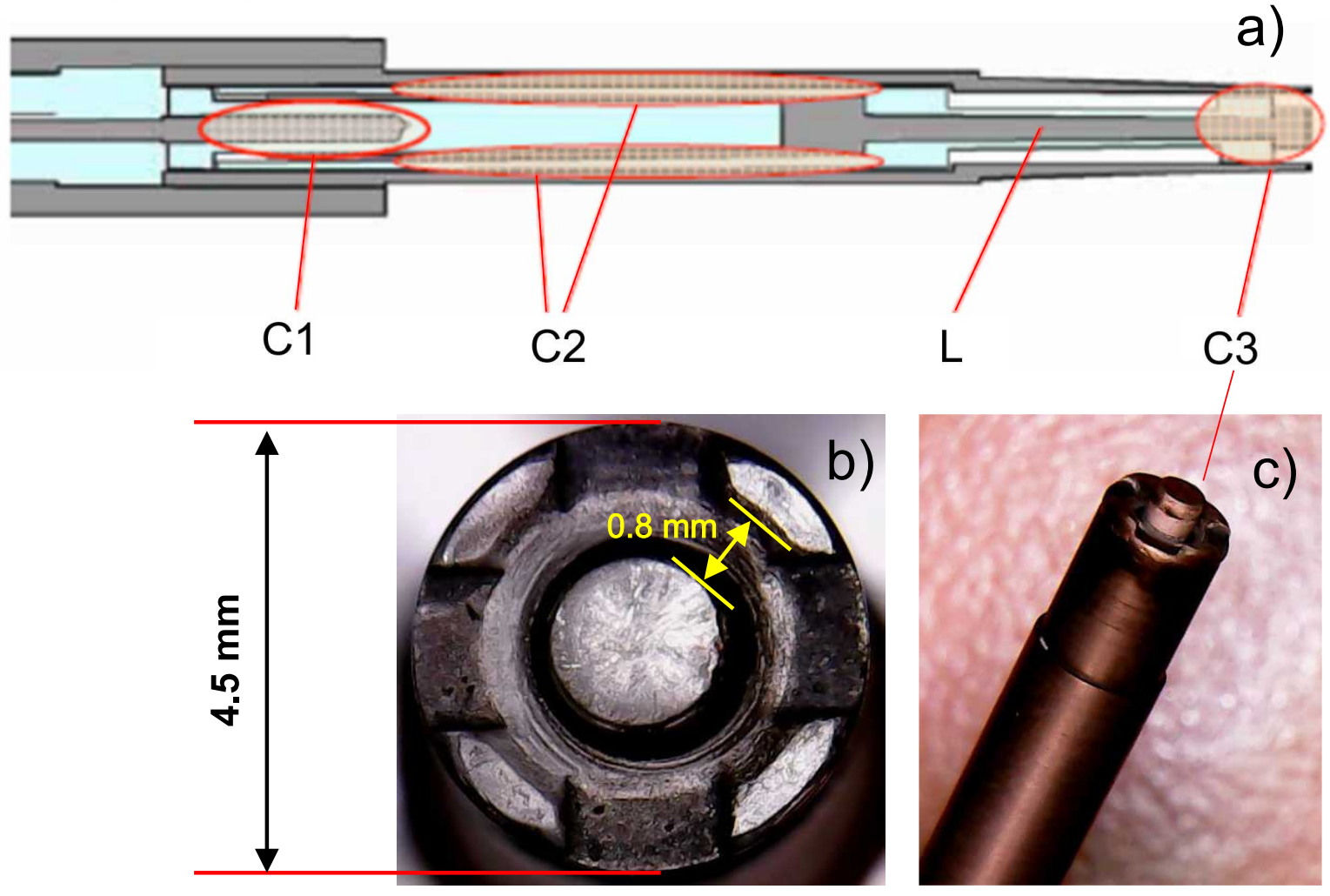

Figure 3. The microwave igniter :a) general scheme; b) the front view; c) the side view.

The major part of the experiments was performed in nitrogen $(<100 \mathrm{ppm}$ of impurities, Air Liquide). The experiments in $\mathrm{N}_{2}: \mathrm{O}_{2}=8: 2(<100 \mathrm{ppm}$ of impurities, Air Liquide) and $\mathrm{N}_{2}: \mathrm{O}_{2}: \mathrm{CO}_{2}=79: 13: 8\left(\mathrm{CO}_{2}\right.$ with $<600$ ppm of impurities, Air Liquide $)$ mixtures were carried out to confirm and to generalize the conclusions obtained for the discharge in nitrogen.

\section{Results and discussion}

2.1. Discharge morphology, typical spectra and ratio of emission of molecular bands of nitrogen

The ICCD images of plasma created by MDI discharge in pure nitrogen at atmospheric pressure are presented in figure 4, and corresponding spectra are given by figure 5 .

Optical emission of plasma produced during the breakdown is concentrated in a single bright spot between the electrodes, a typical visible diameter of the plasma is being less than $1 \mathrm{~mm}$. Optical emission of the breakdown pulse contains mainly atomic 


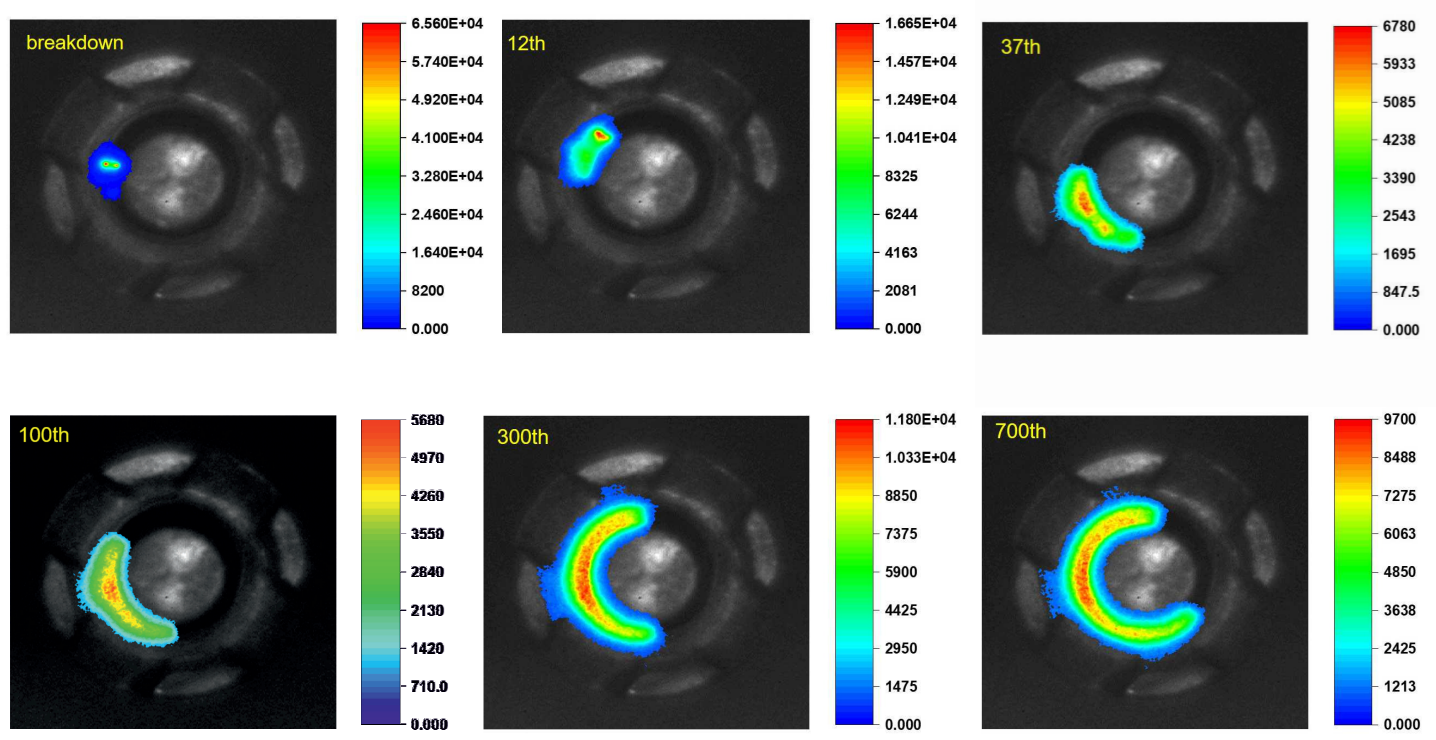

Figure 4. ICCD images of MDI plasma in atmospheric pressure nitrogen. ICCD camera gate is equal to $5 \mu$ s for the breakdown pulse and $300 \mathrm{~ns}$ for the rest of the pulses. The pulses are numbered in the frames starting from $N=1$ in the second burst. The images are taken in a single shot mode for different experiments for one atmosphere of nitrogen.

lines of material of the electrodes. No strong CW component of the spectrum is observed.

In the second burst of pulses, the plasma is more volumetric: a typical length of the plasma pattern is equal to a few $\mathrm{mm}$ (up to $5-7 \mathrm{~mm}$ ); the discharge spreads from one outer electrode to another in the angular direction, filling the interelectrode space in the most possible uniform way (see figure 4,300 th-700th pulses). At the end of the burst in the most of experiments the discharge occupies about $120^{\circ}$ of the interelectrode ring. The appearance of the discharge slightly is different from experiment to experiment, the discharge is not attached to defects on the electrode. Selectrion of the pulse for further measurements is illustrated by figure 6 presenting the emission in the wavelength range $340 \pm 5 \mathrm{~nm}$ measured by the photomultiplier.

In the spectrum, the role of emission of molecular bands increases with the number of pulse. Already in the first pulse (see figure 5) the molecular bands of the second positive system of molecular nitrogen $\left(\mathrm{N}_{2}\left(\mathrm{C}^{3} \Pi_{u}\right) \rightarrow \mathrm{N}_{2}\left(\mathrm{~B}^{3} \Pi_{g}\right)\right.$ transition) are clearly seen between 300 and $400 \mathrm{~nm}$, but three strongest atomic lines of Mo (375 - $400 \mathrm{~nm})$ still dominate in the spectrum. In the 100th pulse, only the bands of the second positive and the first negative $\left(\mathrm{N}_{2}^{+}\left(\mathrm{B}^{2} \sum_{u}^{+} \rightarrow \mathrm{X}^{2} \sum_{g}^{+}\right)\right.$transition) systems of molecular nitrogen are present in the spectrum.Emission integrated afters significant part of the discharge, to avoid local none uniformities, was analyzed. The maximum amplitude of emission in the pulse is observed at about $17 \mu \mathrm{s}$, that is in about 12th pulse (figure 6 a). Then the amplitude of the emission decreases and a quasi-stationary picture is observed starting 

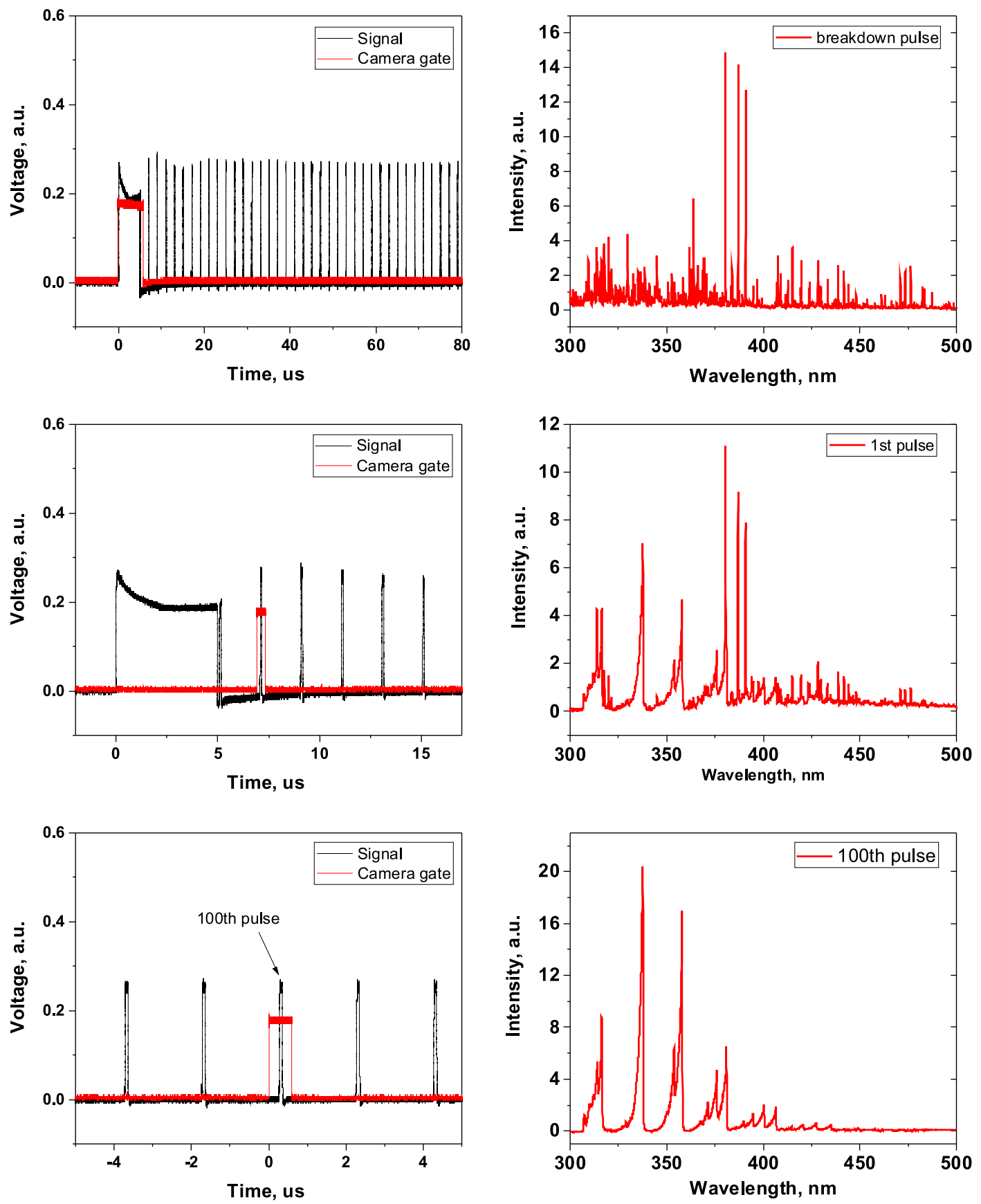

Figure 5. Spectra of MDI plasma in atmospheric pressure nitrogen. ICCD camera gate is equal to $5 \mu \mathrm{s}$ for the breakdown pulse and $600 \mathrm{~ns}$ for the rest of the pulses. The pulses are numbered in the frames similar to figure 4, 0th pulse means the breakdown pulse. Left hand size: schematic presentation of sequence of pulses and ICCD camera gate; right hand size: corresponding emission spectra for one atmosphere of nitrogen.

from $35-40 \mu \mathrm{s}$. The shape of the emission pulse changes depending on pulse number. This fact is shown in figure $6 \mathrm{~b}$ : for $N=1$, the emission pulse is practically squared with the duration equal to $t_{W}$. Then, for $N=5,9$ and 12 the emission peak on the 

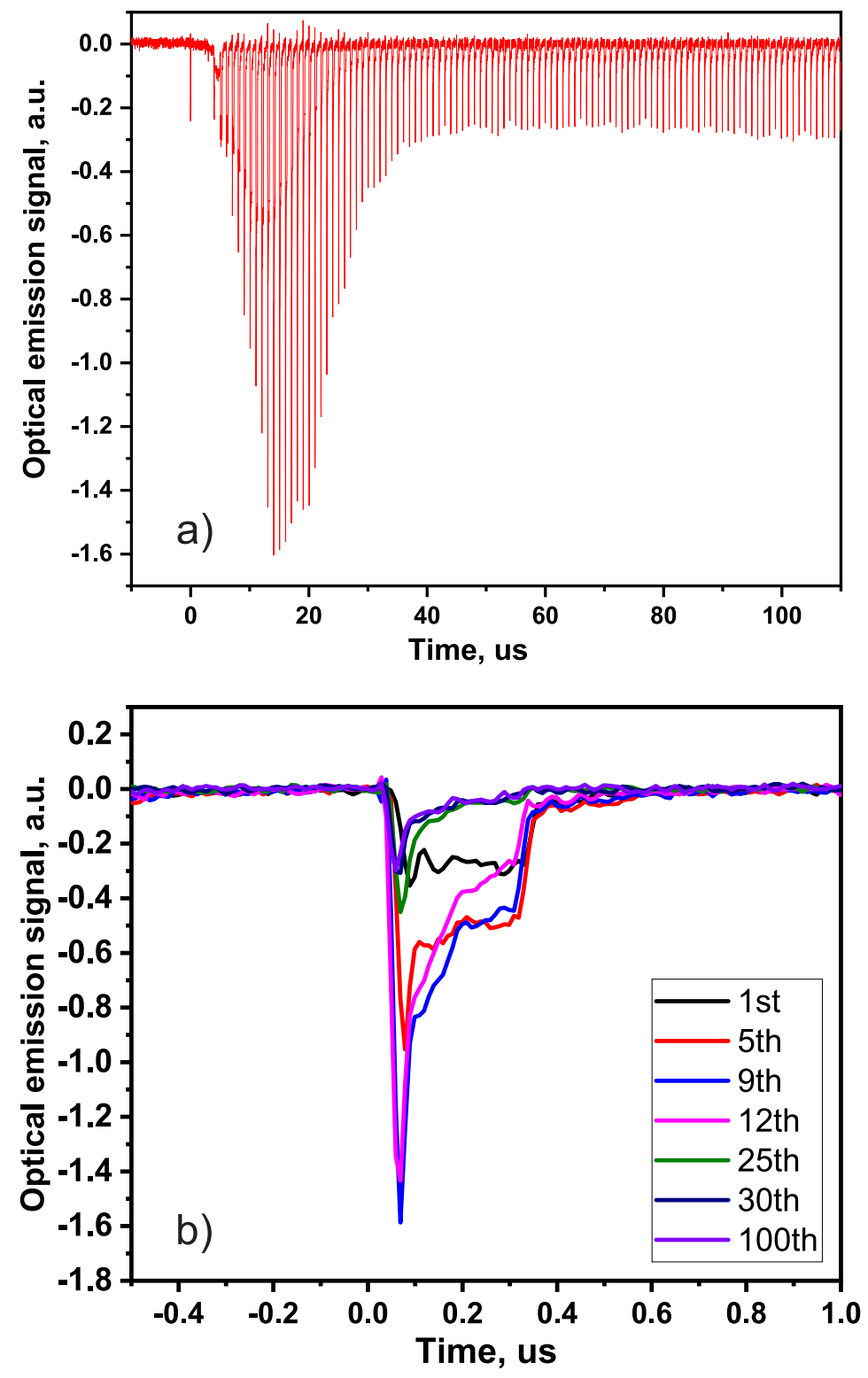

Figure 6. Temporal behavior of emission at $\lambda=340 \pm 10 \mathrm{~nm}$ : (a) general picture; (b) waveforms of emission corresponding to different pulses in the second burst for one atmosphere of nitrogen

front of the pulse is clearly distinguished. We suppose that this peak corresponds to the propagation of the ionization wave in the inter-electrode space, that is to spreading of the discharge. The ratio of the amplitudes of the signal in the peak and on the plateau is $35: 10$. Finally, for $N=25,30$ and 100 , the amplitude of the emission is low and practically constant; the emission corresponds mainly to the front of the pulse and no emission is observed after the front: the ratio of the amplitudes of the signal in the peak 
and on the plateau is $50: 10$.

Two transitions of molecular nitrogen were selected to analyze the electric field: $\mathrm{N}_{2}^{+}\left(\mathrm{B}^{2} \Sigma_{g}^{+}, v^{\prime}=0\right) \rightarrow \mathrm{N}_{2}^{+}\left(\mathrm{X}^{2} \Sigma_{g}^{+}, v=0\right), 391.4 \mathrm{~nm}$, or the first negative system (FNS) and $\mathrm{N}_{2}\left(\mathrm{C}^{3} \Pi_{u}, v^{\prime}=2\right) \rightarrow \mathrm{N}_{2}\left(\mathrm{~B}^{3} \Pi_{g}, v^{\prime \prime}=5\right), 394 \mathrm{~nm}$, or the second positive system (SPS). A peculiarity of $v^{\prime}=2 \rightarrow v^{\prime \prime}=5$ transition is that it is situated near the FNS $v^{\prime}=0 \rightarrow v^{\prime \prime}=0$ transition and $391.4 \mathrm{~nm}$, and so no additional calibration of the spectral system is needed. The details of the procedure can be found elsewhere [23,24]. It was suggested that (i) the discharge is spatially uniform, that is that the emission of the FNS and of the SPS comes from the same spatial region; (ii) the electric field is constant over the pulse; (iii) the excitation of the FNS and of the SPS happens in direct collisions with electrons; (iv) that quenching of the excited states is due to collisions with non-excited $\mathrm{N}_{2}$ molecules. As far as these conditions are not necessarily fulfilled in the pulsed MW plasma, the ratio of the bands should be considered as the experimental parameter, and for the electric field calculated from the experimentally obtained ratio, the term "efficient reduced electric field", similar to [25], will be further used.

An example of spectrum containing the SPS and the FNS band, is given in the insert to Figure 7. To obtain the value of the efficient reduced electric field, $(E / N)_{\text {eff }}$, the spectra have been treated in the following way: the SPS was fitted using Specair code [22] and extracted from the experimentally obtained spectrum : the shape and amplitude of the FNS band at $391.4 \mathrm{~nm}$ were so obtained. The FNS and the SPS bands at $391.4 \mathrm{~nm}$ and $394 \mathrm{~nm}$ were integrated each over the corresponding band. The obtained ratio was compared to calibration curve from [23] taking into account quenching

of $\mathrm{N}_{2}\left(\mathrm{C}^{3} \Pi_{u}\right)$ and $\mathrm{N}_{2}^{+}\left(\mathrm{B}^{2} \Sigma_{g}^{+}\right)$by $\mathrm{N}_{2}$ molecules. The resulting efficient electric field is plotted in figure 7 .

It is seen from the figure that the ratio of emission, $R_{391} / R_{337}$ drops down significantly with the number of pulse, from 0.42 in 10 th pulse to 0.08 in 300 th pulse. In the 100th pulse, the efficient reduced electric field is equal to $270 \mathrm{Td}$; in the case of uniform plasma and one-step excitation by electron impact, the measured ratio of intensities corresponds to the mean electron energy about $6.3 \mathrm{eV}$. So high values of electric field can hardly be kept in the discharge during $t_{W}$, the high electric fields are rather typical for the front of each discharge pulse.

\subsection{Parametrical study of $T_{r o t}$ and $T_{v i b}$ at changes of parameters of $M W$ power}

The bands of molecular nitrogen appearing in the spectra and the high ratio of $R_{391} / R_{394}$ indicate that the electron energy stays high in all the sequence of the second burst of pulses. Pulse N100 ( $1 \mu$ s from the start of the burst) was selected to measure rotational $T_{\text {rot }}$ and vibrational $T_{v i b}$ temperatures of molecular nitrogen. The measurements were made in atmospheric pressure nitrogen. The MW pulse duration, $t_{w}$, and the time period between the pulses, $t_{p}$, where the parameters of the study.

Figures 8 shows the raw experimental data for the measurements of rotational temperature for different pulse periods $t_{p}$ at fixed pulse width $t_{W}=100 \mathrm{~ns}=$ const. 


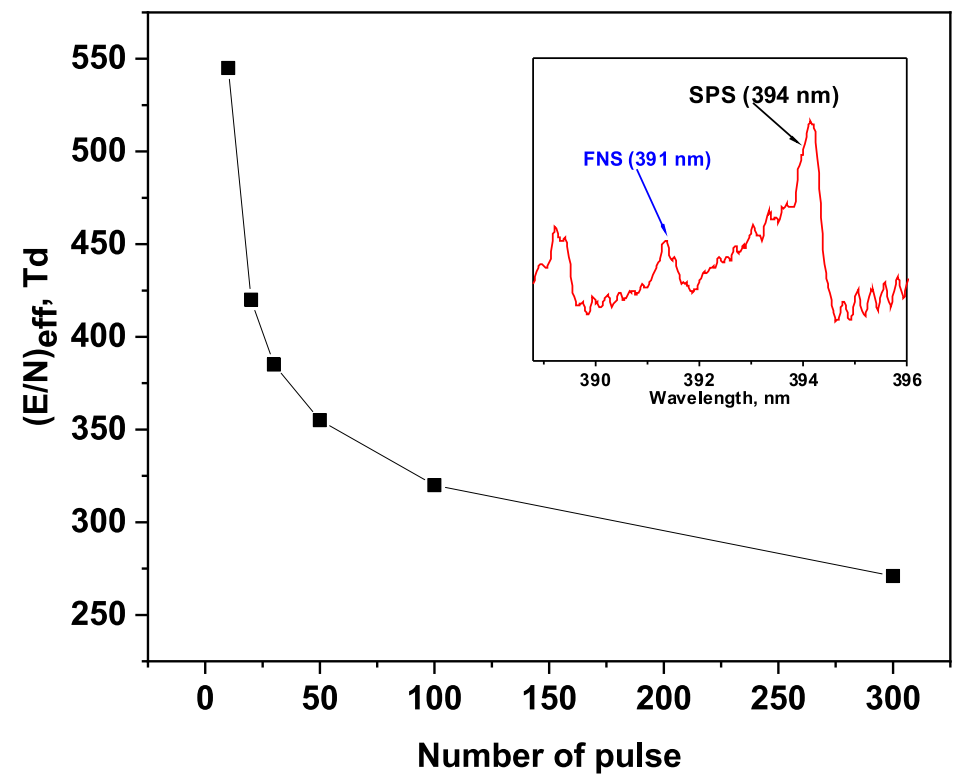

Figure 7. Electric field vs number of pulse. A part of spectrum used to measure the electric field is presented in the insert. Nitrogen, $P=1 \mathrm{~atm}$.

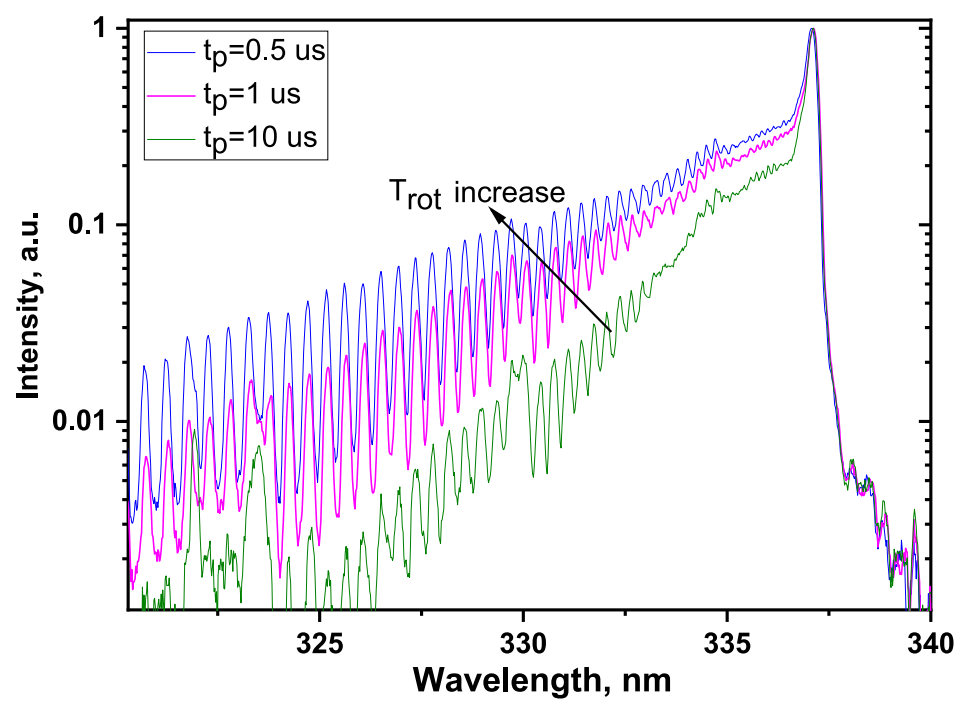

Figure 8. Example of experimental raw data for $T_{\text {rot }}$ measurements: spectrum corresponding to the $v^{\prime}=0 \rightarrow v^{\prime \prime}=0$ transition of the SPS of molecular nitrogen for different $t_{p}$ at fixed $t_{W}=100 \mathrm{~ns}$. Nitrogen, $\mathrm{P}=1 \mathrm{~atm}$.

Decrease of $\mathrm{T}_{r}$ ot with increase of the period $t_{p}$ is clearly seen. The accuracy of measurements of $\mathrm{T}_{\text {rot }}$ in the present work was estimated as $\pm 150 \mathrm{~K}$. 

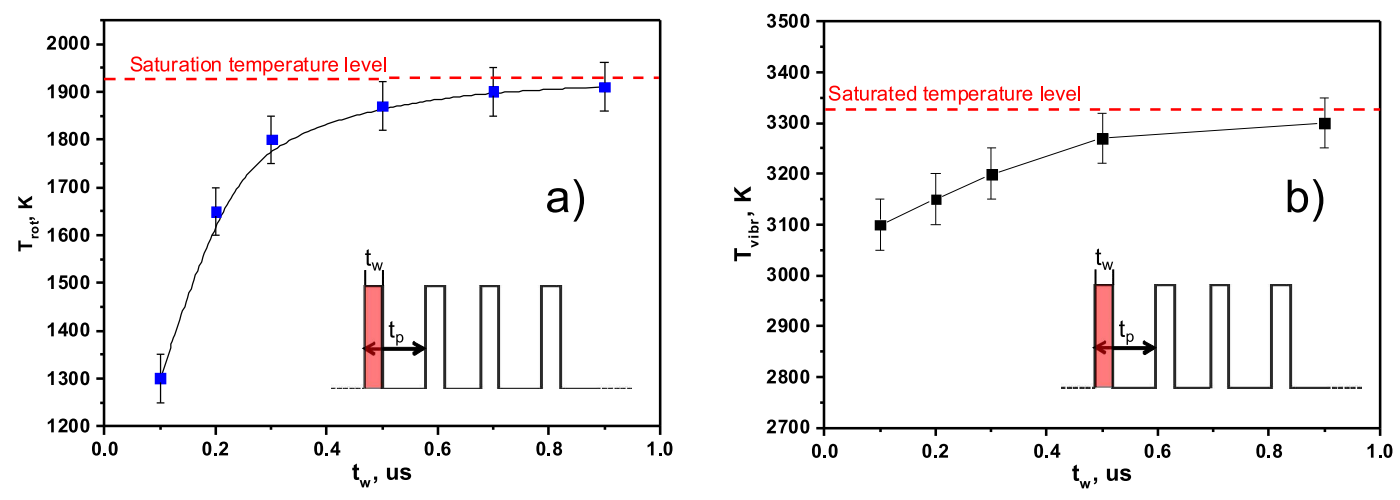

Figure 9. (a) Rotational temperature and (b) vibrational temperature on the $\mathrm{N}_{2}\left(\mathrm{C}^{3} \Pi_{u}\right)$-state for $t_{p}=1 \mu \mathrm{s}=$ const at changing $t_{W}$. Nitrogen, $\mathrm{P}=1 \mathrm{~atm}$.
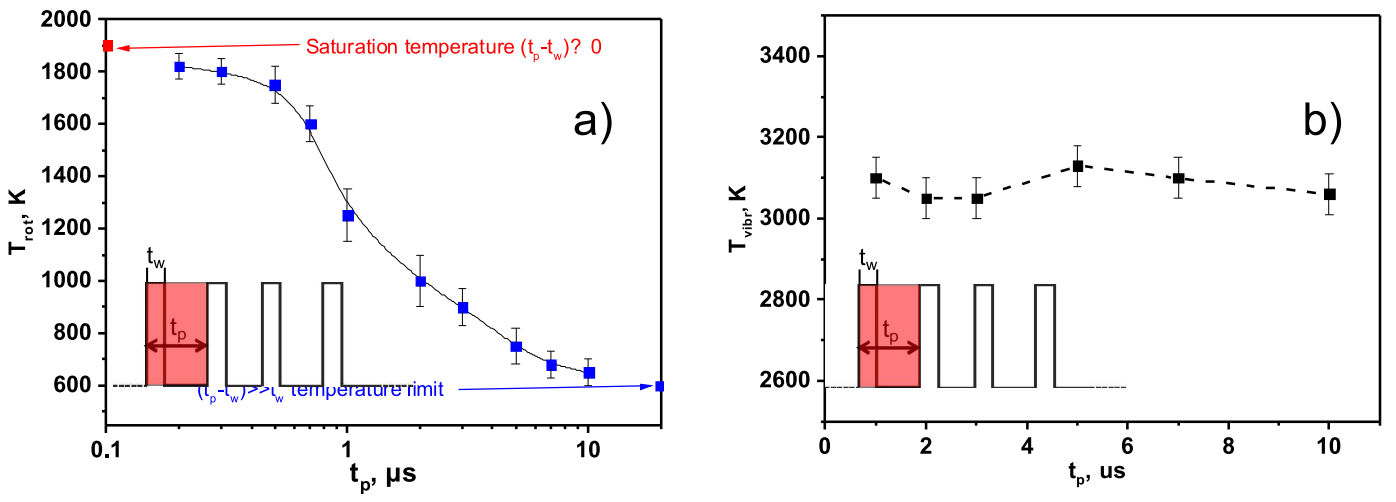

Figure 10. (a) Rotational temperature and (b) vibrational temperature on the $\mathrm{N}_{2}\left(\mathrm{C}^{3} \Pi_{u}\right)$-state for $t_{W}=100 \mathrm{~ns}=$ const at changing $t_{p}$. Nitrogen, $\mathrm{P}=1 \mathrm{~atm}$.

Behavior of the rotational and the vibrational temperatures on the $\mathrm{N}_{2}\left(\mathrm{C}^{3} \Pi_{u}\right)$-state for $t_{p}=1 \mu \mathrm{s}=$ const at $t_{W}$ changing in a broad range is presented in Figure 9. With increase of $t_{W}$ from 0.1 to $0.9 \mu \mathrm{s}$, the rotational temperature increases from $1200 \mathrm{~K}$ to an asymptotic value, $\mathrm{T}_{\text {rot }} \sim 1930 \mathrm{~K}$. Vibrational temperature increases from $\mathrm{T}_{v i b}=3100 \mathrm{~K}$ to $\mathrm{T}_{v i b}=3300 \mathrm{~K}$.

Behavior of the rotational and the vibrational temperatures on the $\mathrm{N}_{2}\left(\mathrm{C}^{3} \Pi_{u}\right)$-state for $t_{W}=100 \mathrm{~ns}=$ const at changing $t_{p}$ is presented in Figure 10. With decrease of $t_{p}$ from 10 to $0.1 \mu \mathrm{s}$, the rotational temperature increases from $650 \mathrm{~K}$ to an asymptotic value, $\mathrm{T}_{\text {rot }} \sim 1800 \mathrm{~K}$. Vibrational temperature is much higher, $T_{v i b} \approx 3050 \mathrm{~K}$, and practically does not change when changing the $t_{p}$.

For both test cases, corresponding to changing $t_{p}$ or $t_{W}$, the ratio $\mathrm{T}_{v i b}>>\mathrm{T}_{\text {rot }}$ is valid. It is possible to maximize $T_{v} i b / T_{r}$ ot ratio, decreasing the pulse duration $t_{w}$ or increasing the time period $t_{p}$. To check if this conclusion stays correct at pressure increase, similar experiments have been performed for a wide pressure range. 


\subsection{MDI discharge development and plasma parameters at pressure increase}

The ICCD images of the discharge in nitrogen at different pressures are presented in figure 11, the left column. At 0.2 bar the emission fills uniformly the interelectrode space; at 1 bar the discharge still spreads in the angular direction covering the angle about 190 - 200 degrees; at 3 bar the discharge transforms to a contracted filament between the two electrodes; from pulse to pulse the position of the discharge changes in a non-regular way. For any gas pressure, the emission intensity after 50th-60th pulse changes only slightly. The pulse N100 was selected for the spectral analysis.

The review spectra in the wavelength range $\lambda=300-450 \mathrm{~nm}$ are given in figure 11, the right column. At atmospheric pressure and at $P=1.5 \mathrm{bar}$, the spectrum presents a classical example of emission of the second positive system in molecular nitrogen. Starting from $P=2$ bar, atomic lines appear in the spectra $(\lambda=330,241,412 \mathrm{~nm}$ etc); their intensity slowly increases with pressure. The concentration of the discharge energy with pressure ("contraction" of the discharge) can provide, in spite of gas density increase with pressure, the higher specific energies, in particular - the higher specific energies near the electrodes. As a result, sputtering of material of the electrodes is observed. Another element of the spectra originating at high pressures, is emission of $\mathrm{CN}$ radical. The $\mathrm{CN}$ emission bands are typical for high-temperature reactive media; for example, they are observed under re-entry conditions, and indicate the presence of high temperatures, typically units of $\mathrm{kK}$. Appearing at $P=2$ bar and progressively
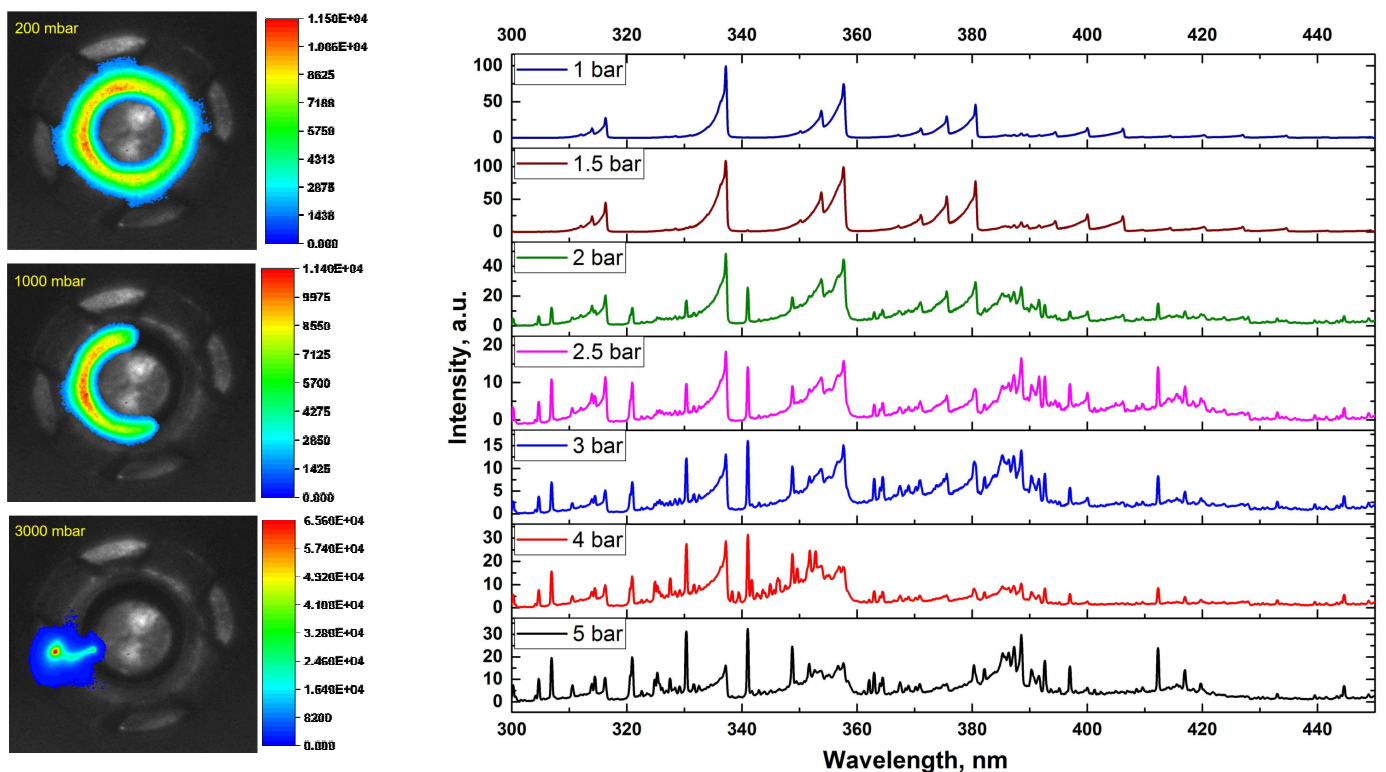

Figure 11. Left hand side: ICCD images of the discharge in molecular nitrogen at different pressures; ICCD camera gate is equal to $1 \mu \mathrm{s}$. Right hand side: review spectra $(300-450 \mathrm{~nm})$ of optical emission from the discharge with pressure increase. Pure nitrogen. Pulse $N=100$. 


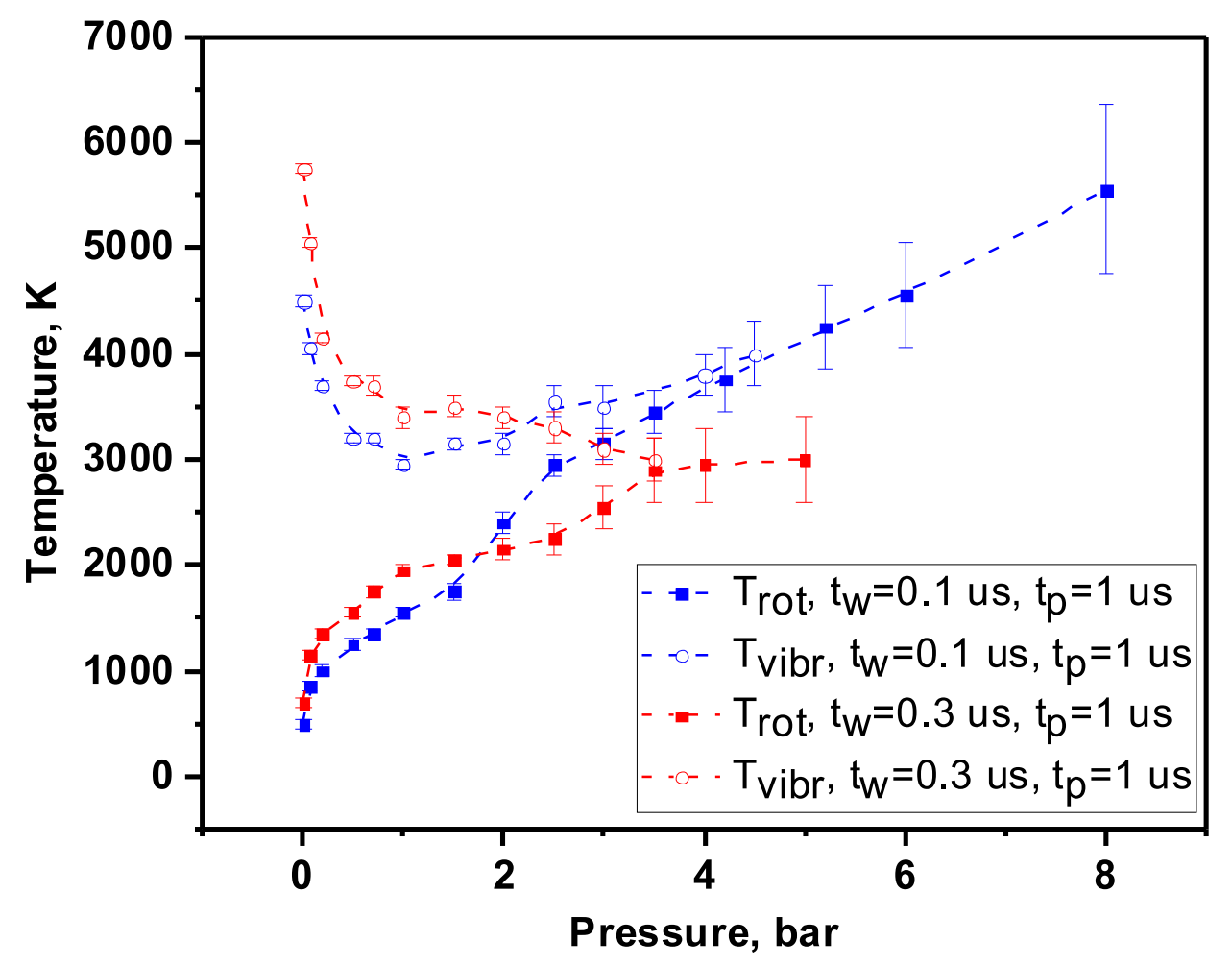

Figure 12. Rotational, $T_{\text {rot }}$, and vibrational, $T_{v i b}$, temperatures for two different values of $t_{W}$ at $t_{p}=1 \mu \mathrm{s}$ : evolution with pressure. Pure nitrogen.

increasing with pressure, the molecular bands between 380 and $400 \mathrm{~nm}$ belong to CN molecular bands; C-atoms, the most probably, are sputtered from the surface of the dielectric.

Figure 13 summarizes the data for the measured rotational, $\mathrm{T}_{\text {rot }}$, and vibrational, $\mathrm{T}_{v i b}$, temperatures, in pure nitrogen. The evolution of the temperature with pressure for two different values of $t_{W}$, namely $t_{W}=100 \mathrm{~ns}$ (blue curves) and $t_{W}=300 \mathrm{~ns}$ (red curves) at $t_{p}=1 \mu \mathrm{s}=$ const is presented in the plot. The most important conclusion from the figure is that, starting from some pressure, the temperatures are equal: $\mathrm{T}_{\text {rot }}=\mathrm{T}_{\text {vib }}$. This happens at $P=3.5$ bar for $t_{W}=300 \mathrm{~ns}$ and at $P=5$ bar for $t_{W}=100 \mathrm{~ns}$. It is important to note is that with pressure increase (i) the gas temperature increases (the temperature at our conditions is equal to $\mathrm{T}_{\text {rot }}$ ); (ii) the rate of $\mathrm{VT}$-relaxation increases due to increase of the gas temperature. A typical time of VT-relaxation $\tau_{V T}$ on nitrogen molecules at $\mathrm{T}=500 \mathrm{~K}$ is equal to hundreds of seconds, and at $\mathrm{T}=3000 \mathrm{~K}$ is equal to $\tau_{V T}^{3000} \sim 10 \mu \mathrm{s}$. Increase of gas temperature of the discharge, due to energy relaxation from the electronic degrees of freedom (so called fast gas heating) and starting VT-relaxation, accelerates the rate of the VT-relaxation; vibrational temperature goes down, rotational and gas temperatures increase, and finally, a partial equilibrium is 

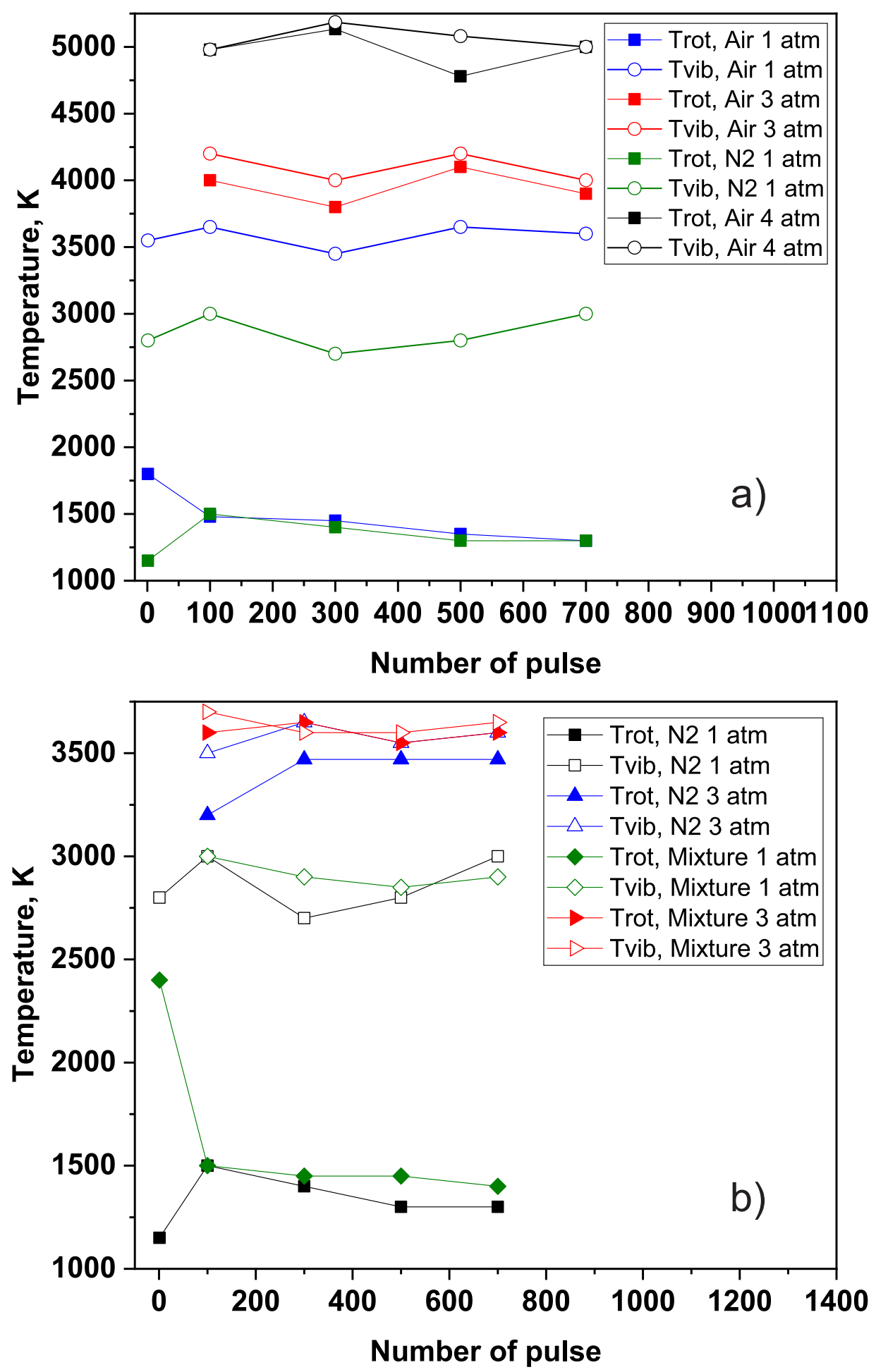

Figure 13. Rotational, $T_{\text {rot }}$, and vibrational, $T_{v i b}$, temperatures: a) pure nitrogen, $\mathrm{P}=1 \mathrm{~atm}$ and air; b) pure nitrogen and $\mathrm{N}_{2}: \mathrm{O}_{2}: \mathrm{CO}_{2}=79: 13: 8$ mixture. 
reached at a few bars: $\mathrm{T}_{\text {gas }}=\mathrm{T}_{\text {rot }}=\mathrm{T}_{\text {vib }}$.

It should be noted that the electron temperature, estimated from the ratio of the emission bands of the first negative and the second positive systems of molecular nitrogen at $391.4 \mathrm{~nm}$ and $394 \mathrm{~nm}$ as descried above, demonstrate high values of the efficient reduced electric field $(E / N)_{\text {eff }} \approx 400 \mathrm{Td}$ in the 100th pulse at low pressures, $\mathrm{P}=0.2$ mbar, falling down to about $(E / N)_{\text {eff }} \approx 200 \mathrm{Td}$ already at $P=20 \mathrm{mbar}$, and changing only slightly with further pressure increase to $P=2.5 \mathrm{bar}$. This value corresponds to electron energy $T_{e} \sim 5 \mathrm{eV}$ in pure nitrogen. At $P>2.5 \mathrm{bar}$, the emission spectrum is polluted by CN bands at $\lambda=390-400 \mathrm{~nm}$, and so the estimates of the electric field at higher pressures are not possible.

\subsection{Plasma parameters in different gas mixtures}

Similar measurements have been performed for air and for $79 \% \mathrm{~N}_{2}: 13 \% \mathrm{O}_{2}: 8 \%$ $\mathrm{CO}_{2}$ mixture in the pressure range $\mathrm{P}=1-4$ atm. Figure 13 presents a summary of the results obtained for $\mathrm{T}_{\text {rot }}$ and $\mathrm{T}_{\text {vib }}$ in different gases as a function of a pulse number. It is seen, that the rotational and vibrational temperatures are the strong functions of a gas mixture composition but (i) practically do not change starting from $\mathrm{N}=100$; (ii) demonstrate similar behavior with pressure for all considered cases. Measurements in air are presented in figure 13a. At $\mathrm{P}=1 \mathrm{~atm}, \mathrm{~T}_{\text {rot }} \approx 1500 \mathrm{~K}$ and $\mathrm{T}_{\text {vib }} \approx 3500 \mathrm{~K}$. At 4 bar, $\mathrm{T}_{\text {rot }}=\mathrm{T}_{\text {vib }} \approx 5000 \mathrm{~K}$. In nitrogen and $\mathrm{N}_{2}: \mathrm{O}_{2}: \mathrm{CO}_{2}$ mixture temperature increase is slightly less pronounced : $\mathrm{T}_{\text {rot }}=\mathrm{T}_{v i b} \approx 3500 \mathrm{~K}$ at $P=3 \mathrm{~atm}$ comparing to $\mathrm{T}_{r o t}=\mathrm{T}_{v i b} \approx 4000 \mathrm{~K}$ At atmospheric pressure, the MDI plasma in all investigated cases is highly nonequilibrium: up to the end of the sequence of pulses, $\mathrm{T}_{e}>>\mathrm{T}_{\text {vib }}>>\mathrm{T}_{\text {rot }}=\mathrm{T}_{\text {gas }}$. At $\mathrm{P}=3$ atm, some difference between $\mathrm{T}_{\text {vib }}$ and $\mathrm{T}_{\text {rot }}$ is still observed. At $\mathrm{P}=3$ bar and $\mathrm{P}=4$ bar, $\mathrm{T}_{\text {vib }}=\mathrm{T}_{\text {rot }}=\mathrm{T}_{\text {gas }}$, but plasma remains nonequilibrium: the $\mathrm{N}_{2}\left(\mathrm{C}^{3} \Pi_{u}\right)$ emission is observed. Direct excitation of $\mathrm{N}_{2}\left(\mathrm{C}^{3} \Pi_{u}\right)$ from the ground state demands $11.03 \mathrm{eV}$ of energy, and the highest observed $\mathrm{T}_{v i b}=\mathrm{T}_{\text {rot }}$ temperature (air, $\mathrm{P}=4$ bar) corresponds only to $0.5 \mathrm{eV}$. Excitation of molecular bands of $\mathrm{N}_{2}\left(\mathrm{C}^{3} \Pi_{u}\right)$ in the microwave pulses is a direct evidence of nonequilibrium character of plasma.

\section{Conclusions}

Plasma of pulsed microwave discharge $(2.45 \mathrm{GHz})$ in nitrogen, air and $\mathrm{N}_{2}: \mathrm{O}_{2}: \mathrm{CO}_{2}=79: 13: 8$ mixture in the pressure range 0.2 - 8 atm was studied experimentally with the help of time-resolved ICCD imaging and emission spectroscopy.

It was shown that the longer the microwave pulse is, the higher is the probability that the spectrum consists of the material of the electrode. This is the cas for the breakdown pulse, $5 \mu$ s in duration.

In the use of shorter pulses, $t_{w}=100 \mathrm{~ns}$, and the distance between pulses $t_{p}=1 \mu \mathrm{s}$, at the power of the microwave radiation equal to $1.6 \mathrm{~kW}$, the atmospheric pressure plasma is strongly nonequilibrium: $\mathrm{T}_{r o t} \approx 1500 \mathrm{~K} ; \mathrm{T}_{\text {vib }} \approx 3500 \mathrm{~K}$. The vibrational 
temperature changes only slightly while the rotational temperature changes between 600 and $2000 \mathrm{~K}$ when varying the $t_{p} / t_{w}$ ratio. With pressure increase, partial equilibrium is reached : $\mathrm{T}_{\text {rot }}=\mathrm{T}_{\text {vib }}$ at $3-4 \mathrm{~atm}$ and higher.

The results obtained for air and $\mathrm{N}_{2}: \mathrm{O}_{2}: \mathrm{CO}_{2}=79: 13: 8$ mixture are in good correlation with the results obtained for molecular nitrogen: plasma is nonequilibrium at atmospheric pressure; partial equilibrium $\left(\mathrm{T}_{r o t} \simeq \mathrm{T}_{v i b}\right)$ is reached at $\mathrm{P} \sim 3$ atm.

\section{References}

[1] Starikovskaia S 2006 Journal of Physics D: Applied Physics 39 R265

[2] Starikovskiy A and Aleksandrov N 2013 Progress in Energy and Combustion Science 39 61-110

[3] Starikovskaia S 2014 Journal of Physics D: Applied Physics 47353001

[4] Adamovich I, Choi I, Jiang N, Kim J, Keshav S, Lempert W, Mintusov E, Nishihara M, Samimy M and Uddi M 2009 Plasma Sources Science and Technology 18034018

[5] Popov N 2008 Plasma Physics Reports 34 376-391

[6] Popov N 2011 Journal of Physics D: Applied Physics 44285201

[7] Ju Y and Sun W 2015 Progress in Energy and Combustion Science 48 21-83

[8] Alrashidi A M, Adam N M, Hairuddin A A and Abdullah L C 2018 International Journal of Energy Research 42 1813-1833

[9] Popov N 2013 Fast gas heating initiated by pulsed nanosecond discharge in atmospheric pressure air 51st AIAA Aerospace Sciences Meeting including the New Horizons Forum and Aerospace Exposition p 1052

[10] Sens M et al. 2016 Ignition systems for gasoline engines (Springer International Publishing:)

[11] Ikeda Y, Nishiyama A, Wachi Y and Kaneko M 2009 Research and development of microwave plasma combustion engine (part i: concept of plasma combustion and plasma generation technique) Tech. rep. SAE Technical Paper

[12] Ikeda Y, Padala S, Makita M and Nishiyama A 2015 Development of innovative microwave plasma ignition system with compact microwave discharge igniter Tech. rep. SAE Technical Paper

[13] Kogoma M 2003 Journal of Plasma and Fusion Research 79 1000-1001

[14] Sanner M A and Park J Y 1997 Review of scientific instruments 68 1575-1581

[15] Khachan J and Gardner D 1999 Journal of applied physics 86 6576-6579

[16] Rousseau A, Dantier A, Gatilova L, Ionikh Y, Röpcke J and Tolmachev Y 2005 Plasma Sources Science and Technology $\mathbf{1 4} 70$

[17] Tomasini L, Rousseau A, Gousset G and Leprince P 1996 Journal of Physics D: Applied Physics 291006

[18] Golubovskii Y B, Kozakov R, Maiorov V, Meshchanov A, Porokhova I and Rousseau A 2004 Journal of Physics D: Applied Physics $\mathbf{3 7} 868$

[19] Shibkov V M, Shibkova L V, Gromov V G, Karachev A A and Konstantinovskii R 2011 High Temperature 49 155-167

[20] Tendero C, Tixier C, Tristant P, Desmaison J and Leprince P 2006 Spectrochimica Acta Part B: Atomic Spectroscopy $612-30$

[21] Zakharenko O, Kuznetsov A, Slinko V and Sulakshin S 1990 Soviet Journal of Quantum Electronics 20813

[22] URL http://www.specair-radiation.net/index.php

[23] Paris P, Aints M, Valk F, Plank T, Haljaste A, Kozlov K and Wagner H 2005 Journal of Physics D: Applied Physics 383894

[24] Valk F, Aints M, Paris P, Plank T, Maksimov J and Tamm A 2010 Journal of Physics D: Applied Physics 43385202

[25] Stepanyan S, Soloviev V and Starikovskaia S 2014 Journal of Physics D: Applied Physics 47485201 